\title{
SISTEM KESINOMAN BERBASIS ANDROID DI ULU APAD DESA ADAT PAKRAMAN KATUNG
}

\author{
K.O. Saputra ${ }^{1}$, P. A. Mertasana' ${ }^{2}$ IGAP. Raka Agung ${ }^{3}$, Y. P. Sudarmojo ${ }^{4}$, and I. B. G. \\ Manuaba $^{5}$
}

\begin{abstract}
ABSTRAK
Ulu apad adalah system pembagian tugas dalam melaksanakan ayah-ayahan (tugas-tugas) adat yang dipergunakan di Desa Pakraman Katung, Kintamani, Bangli. Beberapa kesinoman menjadi pengatur pelaksanaan ulu apad tersebut. Kesinoman biasanya memberikan informasi kepada orang yang mendapatkan tugas-tugas tertentu. Kesinoman juga mencatat orang-orang yang tidak hadir dalam sebuah petedunan. Kesinoman juga harus memungut denda yang harus dibayar oleh orang-orang yang tidak melaksanakan kewajiban adatnya. Dalam melaksanakan tugasnya, kesinoman menggunakan kertas dalam mencatat setiap aktifitasnya. Dalam memberikan informasi kepada para warga, kesinoman sudah menggunakan teknologi, seperti telepon, sms, ataupun aplikasi chating seperti Whatsapp maupun BBM. Melihat sebaran penggunaan perangkat pintar semakin banyak di warga desa Katung, alangkah baiknya jika pekerjaan kesinoman dirangkai kedalam sebuah system informasi berbasis perangkat pintar yaitu handphone dengan system operasi android. Melalui system ini, kesinoman bisa memberikan informasi kepada para warga melalui handphone, dan para warga juga bisa melihat pengumuman pada handphone mereka. Para warga bisa memberikan verifikasi (datang/tidak) ke sebuah tugas. Kesinoman juga langsung memiliki rekapan denda yang harus dibayarkan oleh masing-masing warga di perangkat handphonenya. Dengan system ini, system ulu apad akan mengikuti tren teknologi tanpa menghilangkan makna adat istiadat yang ada di desa Katung tersebut.
\end{abstract}

Kata kunci : Android, ulu apad, kesinoman, desa katung

\begin{abstract}
Ulu apad is local system used at Desa Pakraman Katung. Some kesinoman arrange the schedule of ulu apad. They ussualy provide information to the desa pakraman member. Kesinoman also record the attendance of the member where at the end kesinoman must collect the fine from the absent person. Kesinoman work in combination fashion bentween manual pencil and paper and using of social media and chat application. Based on these facts and also based on the data that most of people at Katung Village have been familiar with mobile phone, it is hyphotized that developing mobile application for ulu apad information system will be beneficial for kesinoman when they working their job. Through this system, ulu apad will be able to follow the advancement of technology without dispel the adat istiadat at Katung Village.
\end{abstract}

Keywords: E-learning, e-exam, Gapoktan Budhi Luhur, Desa Katung, e-cerdas cermat.

\section{PENDAhuluan}

Desa Katung yang terletak di Kecamatan Kintamani Kabupaten Bangli memiliki sistem adat yang bernama Ulu Apad. Ulu Apad dipergunakan untuk mengatur pembagian tugas adat, seperti mebat,

\footnotetext{
${ }^{1}$ Staf Pengajar Prodi Teknik Elektro Fakultas Teknik Universitas Udayana, okasaputra@ unud.ac.id

${ }^{2}$ Staf Pengajar Prodi Teknik Elektro Fakultas Teknik Universitas Udayana, mertasana@unud.ac.id

${ }^{3}$ Staf Pengajar Prodi Teknik Elektro Fakultas Teknik Universitas Udayana, puturaka@ee.unud.ac.id

${ }^{4}$ Staf Pengajar Prodi Teknik Elektro Fakultas Teknik Universitas Udayana, yanu.prapto@unud.ac.id

${ }^{5}$ Staf Pengajar Prodi Teknik Elektro Fakultas Teknik Universitas Udayana, ibgmanuaba@unud.ac.id
} 
gotong royong, pepesuan, ataupun tugas lainnya. Ulu Apad mengatur urutan-urutan warga baik secara tanggung jawab, tugas, maupun sarana upakara yang wajib dibawa pada saat-saat tertentu (pepesuan). Dalam hierarkinya Ulu Apad Desa Pakraman Katung menugaskan Bendesa Adat, Kelihan Adat, dan Penyarikan Adat dalam mengatur pelaksanaan keseharian adat. Ketiga pemimpin tersebut dibantu oleh beberapa orang kesinoman, Kesinoman Tempek Tengah, Kesinoman Tempek Kaja Kauh, Kesinoman Tempek Kaja Kangin, dan Kesinoman Tempek Kelod Kauh. Kesinoman-kesinoman tersebut memiliki beberapa tugas yaitu: 1) membuat daftar karma dan mengubahnya tiap saat ada karma yang keluar dari Ulu Apad dan ada karma baru yang masuk; 2) memberikan informasi terkait petedunan ataupun pepesuan yang dikenakan ke karma tertentu; 3) mengabsen para warga ditiap kegiatan adat; 4) menghitung denda (dose) tiap warga di tiap-tiap kegiatan; dan 5) memungut denda sesuai dengan jumlah yang harus dibayar oleh warga.

Desa Pakraman Katung mengempon Pura sejumlah 8: Pura Bale Agung, Pura Taman Sari, Pura Puseh Sukamrih, Pura Gunung Sari, Pura Dalem, Pura Dukuh, Pura Taman, dan Pura Dugul. Banyaknya Pura tersebut menyebabkan petedunan di Desa Pakraman Katung sangat banyak volumenya. Para Kesinoman tentunya juga memiliki kesibukan yang tinggi. Sekarang ini, sistem yang dipergunakan oleh para kesinoman adalah menggunakan catatan di buku dan perhitungan dose secara manual. Meskipun beberapa kesinoman sudah menggunakan catatan di computer dengan menggunakan Microsoft Excel, namun hal tersebut tidak banyak membantu karena catatan tersebut tidak bisa dilihat oleh warga kecuali catatan tersebut dicetak. Namun melihat frekwensi perubahan yang dalam hitungan hari, maka pencetakan akan sangat mubasir kalua terlalu sering dilakukan.

Dalam penyampaian informasi kepara warga, kesinoman sudah mulai menggunakan media teknologi informasi, seperti sms, facebook, maupun whatsapp. Namun, media-media tersebut hanya sesuai untuk penyebaran informasi tanpa ada umpan balik dari para warga. Umpan balik disini maksudnya adalah jawaban atau informasi terkait kesediaan hadir yang langsung bisa dipergunakan oleh kesinoman untuk mencatat kedalam catatannya.

Selain hal-hal tersbut diatas, berdasarkan data di facebook Desa Pakraman Katung, grup facebook Desa Katung, para pengguna perangkat mobile di Desa Katung sudah mencapai $80 \%$ dari tiap keluarga yang ada. Hal ini adalah potensi yang bisa diambil dalam memberikan sistem yang lebih baik kepada para kesinoman dalam melaksanakan tugas-tugasnya menjalankan sistem Ulu Apad Desa Pakraman Katung.

\section{METODE PELAKSANAAN}

Untuk mencapai tujuan agar warga desa pakraman katung memiliki dan bisa menggunakan sistem kesinoman berbasis android maka metode yang akan dipergunakan adalah kombinasi dari ceramah, tutorial, pendampingan, dan online help. Ketika ceramah, tutorial, dan launching adalah proses tatap muka dengan warga, maka online help adalah sesi pemberian jawaban atas pertanyaanpertanyaan warga yang dilakukan secara online melalui media chat seperti Whatsapp, Telegram, ataupun Facebook. Diagram metode pelaksanaan bisa dilihat pada Gambar 2.1. 


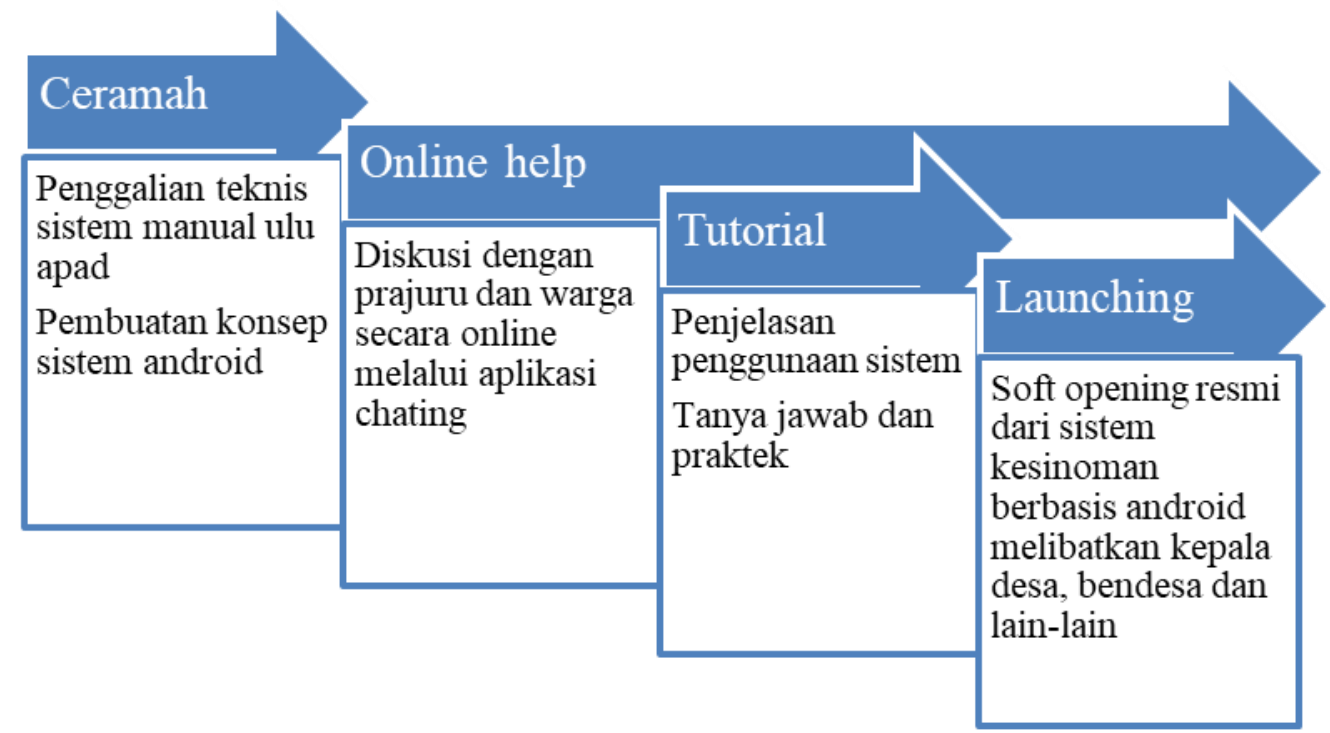

Gambar 2.1. Metode pelaksanaan

\section{HASIL DAN PEMBAHASAN}

Gambar 3.1 dan 3.2 menunjukkan screenshoot dari aplikasi E-Kesinoman versi website yang dibuat untuk menginputkan data awal warga.

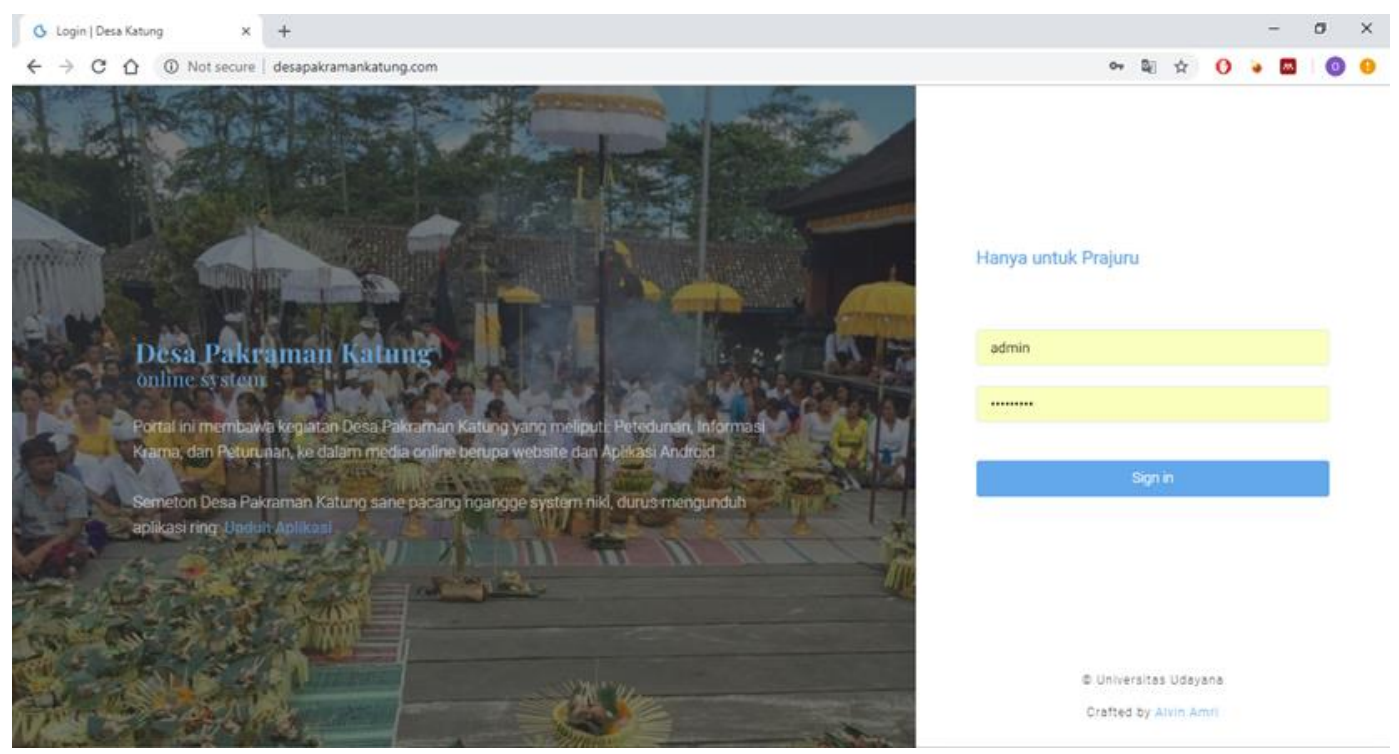

Gambar 3.1 Tampilan menu login admin 


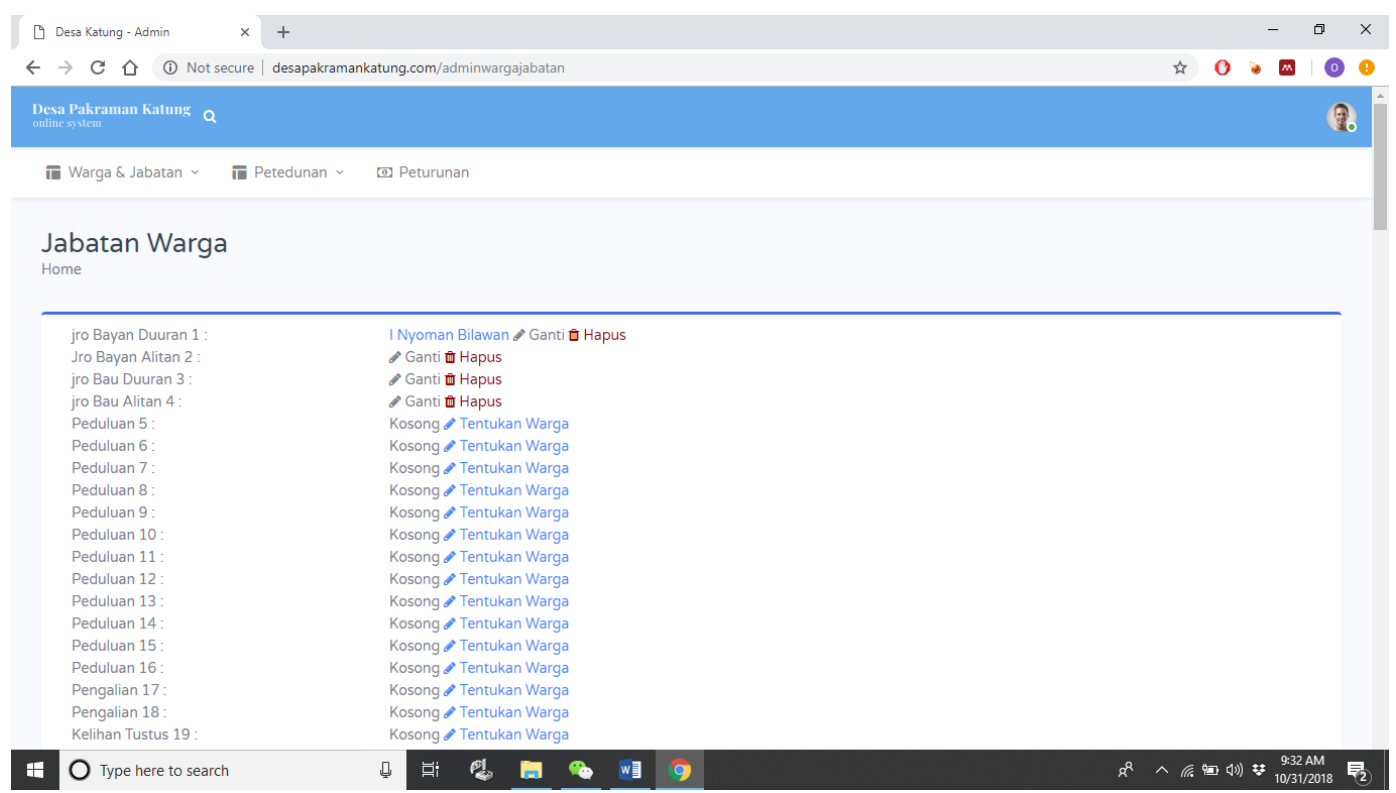

Gambar 3.2 Tampilan menu admin untuk ulu apad

Gambar 3.3 menunjukkan ketika aplikasi E-Kesinoman dipergunakan oleh prajuru dan warga dalam melaksanakan petedunan sedangkan Gambar 3.4 adalah proses peturunan yang dilaksanakan ketika menggunakan E-Kesinoman.

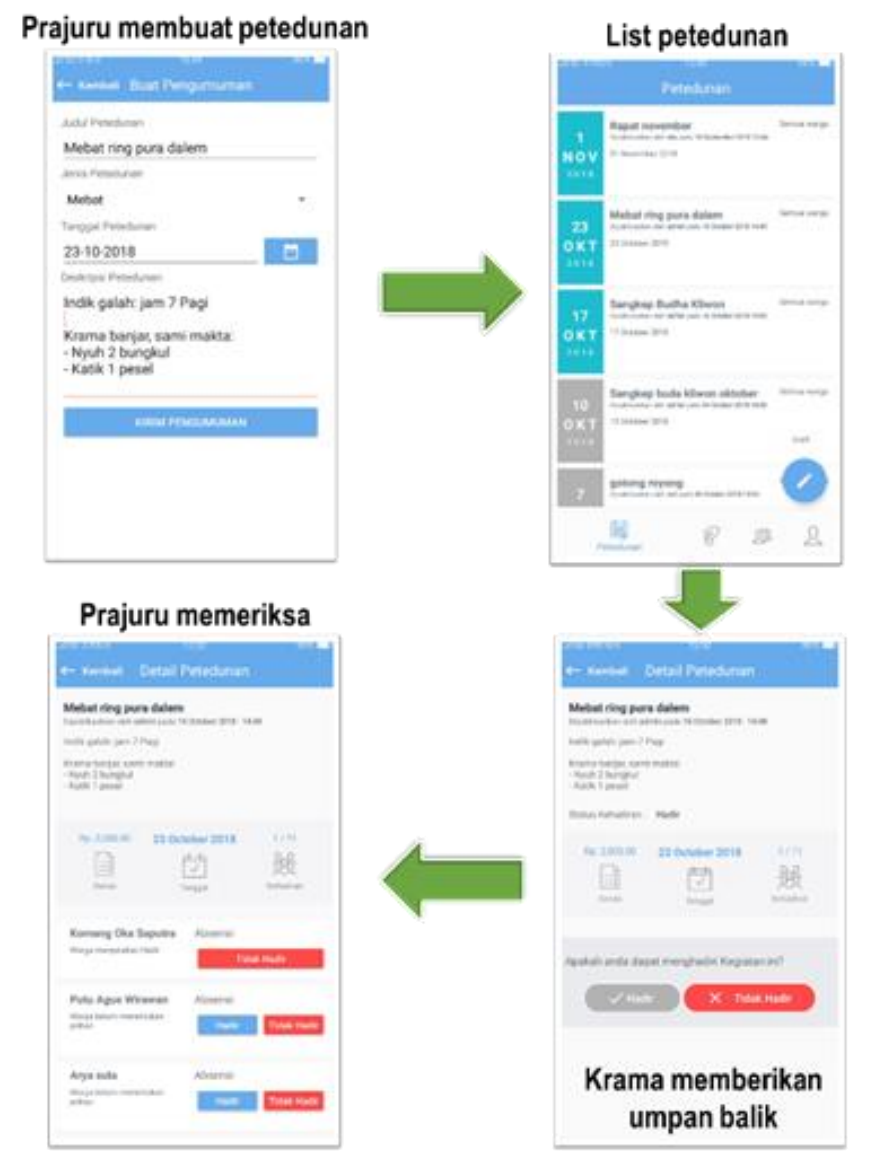

Gambar 3.3. Alur Petedunan pada Aplikasi Android E-Kesinoman 


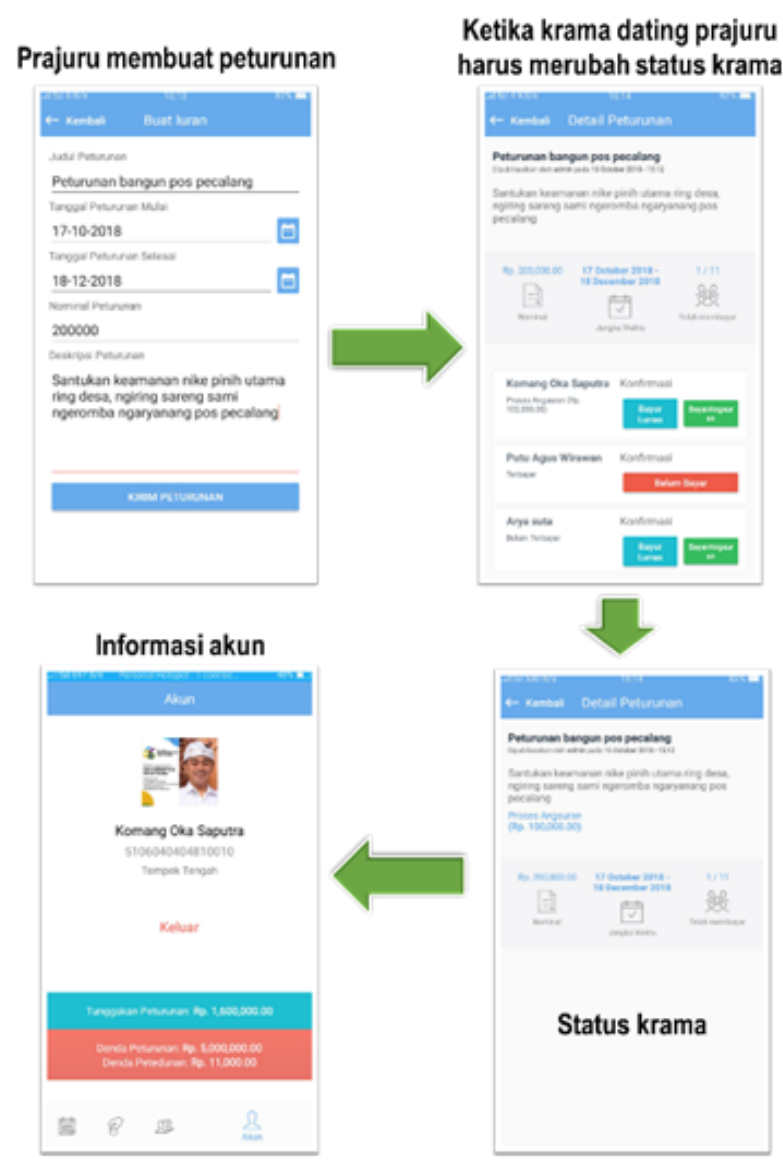

Gambar 3.4. Alur Peturunan pada Aplikasi Android E-Kesinoman

Beberapa photo pelaksanaan sosialisasi dan pelatihan penggunaan E-Kesinoman di Desa Adat Pakraman Katung bisa dilihat pada Gambar 3.5 s/d 3.7

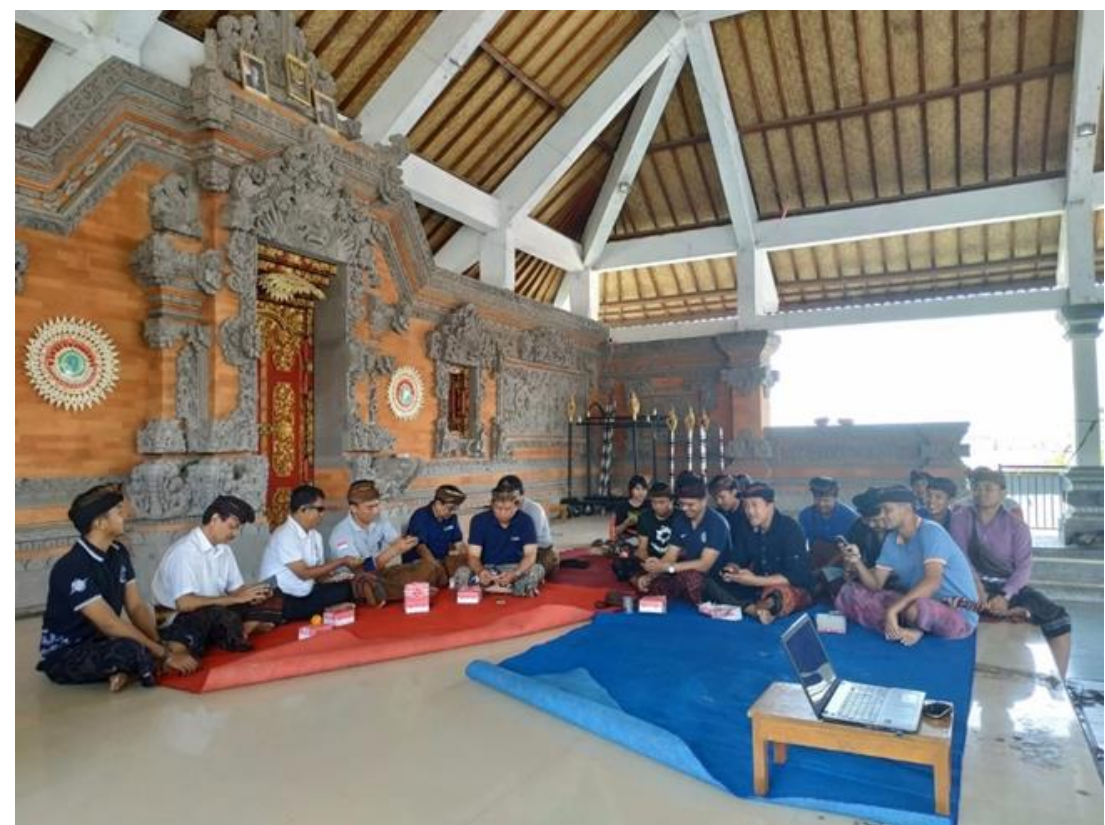

Gambar 3.5. Implementasi di Desa Adat Pakraman Katung \#1 


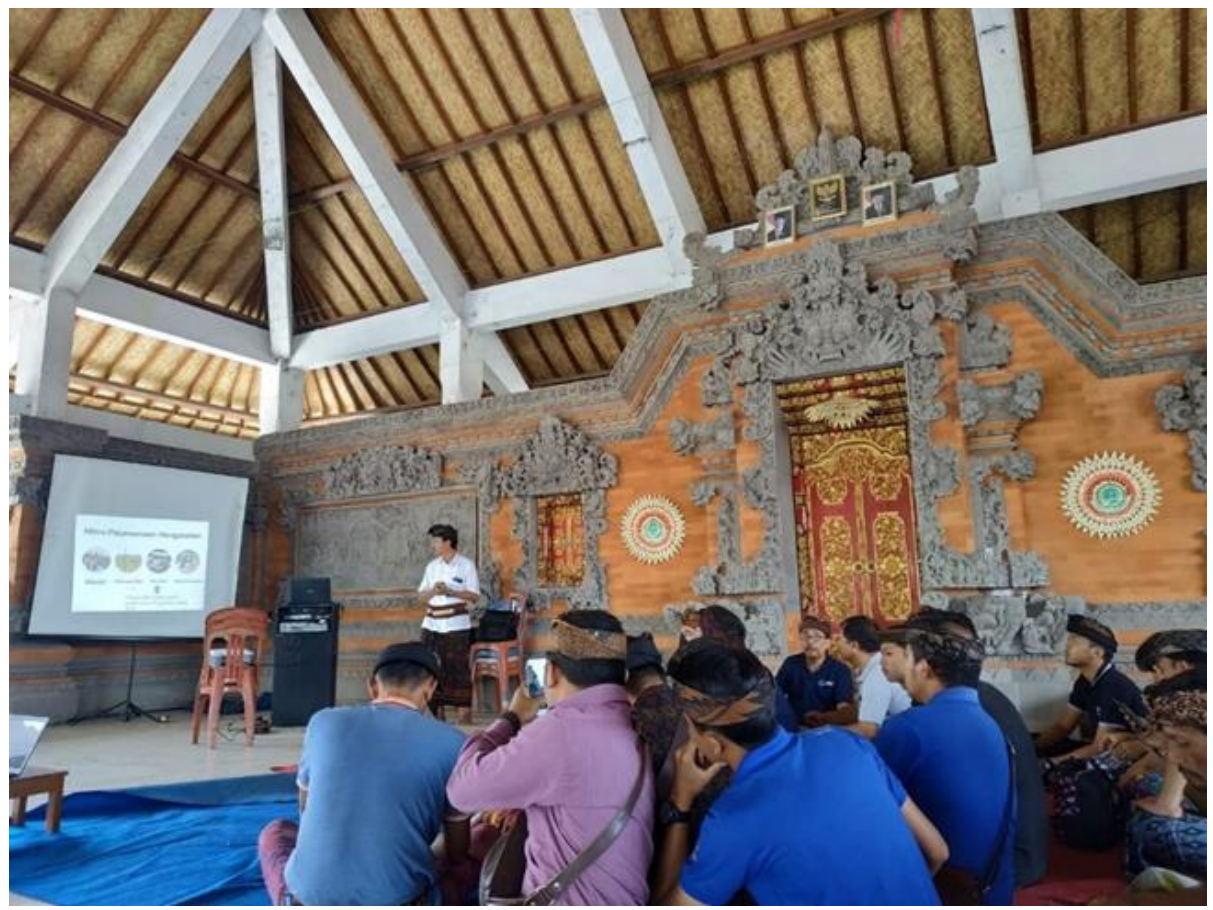

Gambar 3.6. Implementasi di Desa Adat Pakraman Katung \#2

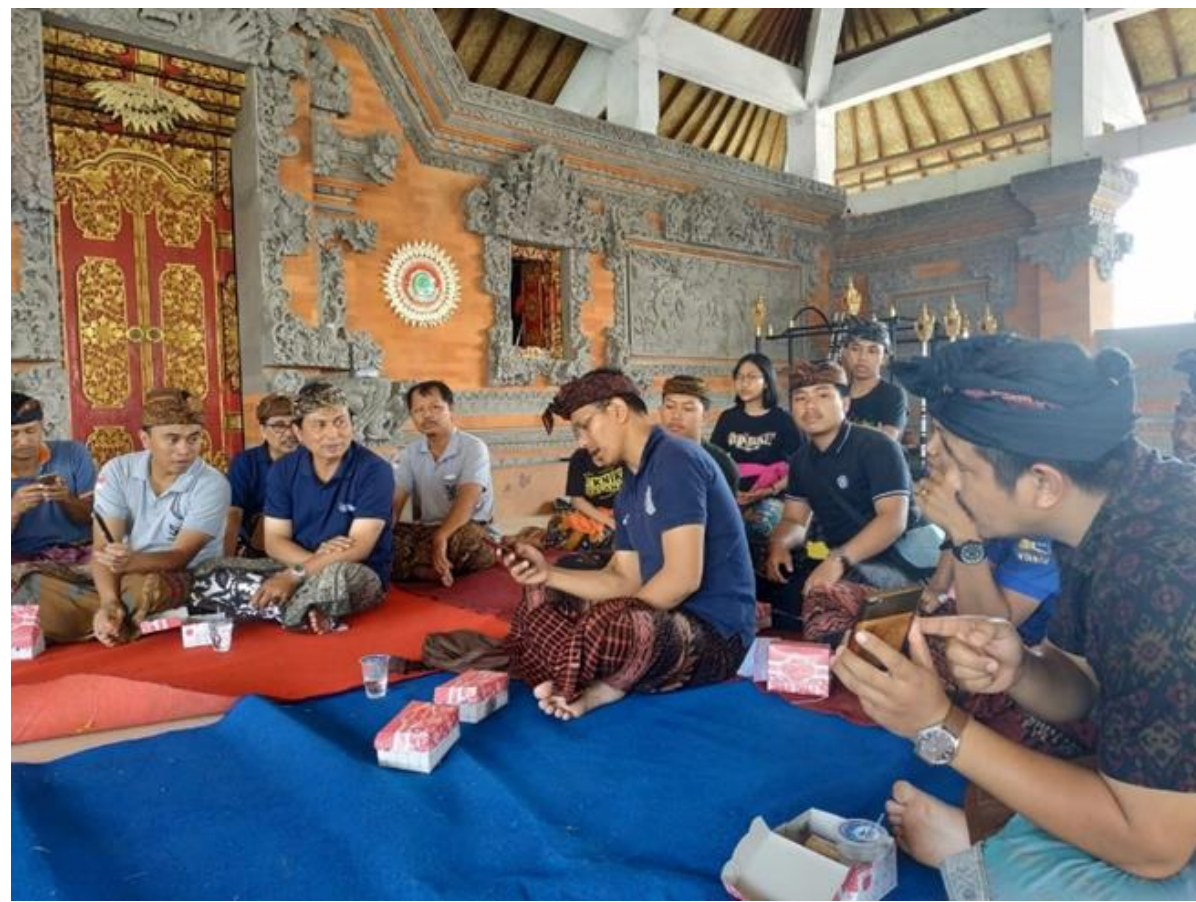

Gambar 3.7. Implementasi di Desa Adat Pakraman Katung \#3

\section{KESIMPULAN DAN SARAN}

Aplikasi E-Kesinoman sudah berhasil dibuat dan diimplementasikan di Desa Adat Pakraman Katung. Prajuru dan warga sangat antusias menggunakan aplikasi ini. Proses pelaksanaan adat memiliki opsi lain dalam penyebaran informasi dan rekap kegiatan selain yang biasa dipergunakan yaitu ditempel di warung-warung. 


\section{DAFTAR PUSTAKA}

Andharini Dwi C., Design an Adaptive E-learning Application Architecture Based on IEEE LTSA Reference Model, TELKOMNIKA, Vol.13, No.1, March 2015, pp. 284 289

Budi, Brian Nurjayanti, "Pengembangan Metode Pembelajaran Online Berbasis E-Learning (Studi Kasus Mata Kuliah Bahasa Pemrograman)”, 07 Jurnal Sains Terapan Edisi II Vol-2 (1) : 103 - 113 (2012)

Bates, A. W. Technology, Open Learning and Distance Education. London: Routledge. 1995 Wulf, K. Training via the Internet: Where are We? Training and Development 50 No. 5. (20 September 2006). 